\title{
Efficacy of chlorhexidine and rosmarinic acid to prevent resin/dentine interface degradation
}

\author{
Kingkaew Ruksaphon and Senawongse Pisol* \\ Department of Operative Dentistry and Endodontics, Faculty of Dentistry, Mahidol University, Thailand
}

\begin{abstract}
The objectives of this study were to evaluate the bond strength and the nanoleakage of resin composite restorations at the resin/dentine interface.

Flat occlusal dentine surfaces were prepared from extracted premolars, etched with phosphoric acid and treated with either $2 \%$ chlorhexidine digluconate (CHX) or $\mu$ M100rosmarinic acid solution (RMA) or were not treated. The specimens were then restored with either three-step (OptiBond ${ }^{\circledR}$ FL) or two-step (OptiBond ${ }^{\star}$ Solo Plus ${ }^{\mathrm{TM}}$ ) etch-and-rinse adhesives and a resin composite. The restored teeth were prepared as hourglass specimens and further divided according to the storage media (pure mineral oil or artificial saliva) and storage time ( 24 hours, 3 months, 6 months, and 1 year). The storage specimens were subjected to a micro-tensile bond strength test and a nanoleakage observation.

The bond strength to dentine of both adhesives without dentine surface treatment decreased after storage in artificial saliva for 3 months to 1 year ( $<<0.05$ ) but did not decrease after storage in pure mineral oil. Dentine surface treatment with either CHX or RMA, under either of the adhesives, was able to postpone the degradation of the bond strength by 3 months $(p<0.05)$. Nanoleakage within the resin-dentine interface bonded without dentine surface treatment increased over time when it was stored in artificial saliva but not in pure mineral oil. Dentine surface treatment with either CHX or RMA prevented nanoleakage only up to 3 months of storage. These findings suggest that effectiveness of MMP-inhibitors in preserving the integrity of the resin-dentine bond is time dependent.
\end{abstract}

\section{Introduction}

Presently, the decreasing of bond strength via hydrolytic and enzymatic degradation at resin-dentine interfaces of dental adhesives over time still be observed [1,2]. The resin-dentine interface remains the weakest area of resin-based dental restorations $[3,4]$.

The degradation of resin-dentine bonded with the three-step etch-and-rinse adhesive after 1 year of immersion in water has been reported caused by the resin elution and alteration of the collagen fibrils [5]. Additional reports on two-step etch-and-rinse adhesives have demonstrated a significant reduction in the micro-tensile bond strength after direct exposure to water for 4 years [6,7]. The bonds produced by etch-and-rinse adhesives were unable to resist deterioration [5-8]. The degradation that occurred in vitro [5-8] could also be observed in vivo [9]. This finding revealed a significant difference in the bond strength of the resin-dentine bond created by etch-and-rinse adhesives that had been aged in an oral environment for 3 years.

The pattern of degradation of the resin-dentine bond with etchand-rinse adhesives occurred within the hybrid layer. It was related to the degradation of the exposed collagen fibrils and was created by a discrepancy between the depth of acid etching and resin infiltration $[5,10]$. Such degradation tends to occur in two-step etch-and-rinse adhesives that combine hydrophilic resin monomers into adhesives that are affected by hydrophilicity. The hybrid layer, when treated with the two-step adhesive, behaves as a semi-permeable membrane and permits water movement along the bonded interface [11], which facilitates the disorganization and hydrolysis of the resin from interfibrillar spaces as well as the degradation of the exposed collagen fibrils within the hybrid layer [5].

In vivo, the degradation causes silver nitrate tracers to penetrate into the hybrid layer around naked collagen fibrils without any gap formation, which occurs due to the resin failing to infiltrate or the residual water not being displaced by the adhesive resin; thus, this penetration might provide or even enlarge the pathways for water, enzymes, or acid to enter the bonded interfaces [12].

The mineralized dentine contains collagenolytic and gelatinolytic enzyme activities, which are thought to be matrix metalloproteinases (MMPs) that can be expressed after the collagen fibrils that are exposed via hydrolysis and leaching form the hybrid layer of resin monomers [13]. The intrinsic MMP activity of the dentine matrix can attack and degrade the collagen, thus causing it to solubilize and increase the water content of the bonded interface and ultimately having a detrimental effect on the longevity of the bond [14].

Because the resin-dentine bond has degraded over time, improving the durability and stability of resin-bonded interfaces on dentine, especially on the inhibition of collagen fibrils degradation, is an interesting topic in adhesive dentistry. Chlorhexidine has been stability of adhesive bonded restorations [15-17]. Currently, rosmarinic acid that could suppress the activities of MMP-2 and MMP-9 has been introduced in adhesive dentistry as effective antioxidant agent [18]. Thus, the effectiveness of rosmarinic acid to prevent collagen

Correspondence to: Pisol Senawongse, Department of Operative Dentistry and Endodontics, Faculty of Dentistry, Mahidol University, 6 Yothi road, Rajthawee District, Bangkok 10400, Thailand, Tel: +66-22007997; Fax: +66-22007988; E-mail: pisol.sen@mahidol.ac.th

Key words: interface degradation, chlorhexidine, rosmarinic acid, nanoleakage, etchand-rinse adhesives

Received: September 02, 2017; Accepted: September 28, 2017; Published: September 30, 2017 
degradation may improve the durability of the resin dentine bond by preserving the collagen fibrils from enzymatic degradation. It was thus of interest to study the effect of chlorhexidine and rosmarinic acid solution by using the combined methodologies of micro-tensile bond strength testing and SEM observations of nanoleakage in the resindentine interface. The null hypothesis of this study was there were no effects of chlorhexidine or rosmaric acid to prevent the enzymatic degradation of resin-dentine interfaces by the micro-tensile bond strength testing and nanoleakage testing with different storage time up to 1 year.

\section{Materials and methods}

This study was approved by the Institutional Review Board of the Faculty of Dentistry and the Faculty of Pharmaceutical Sciences with MU-DT/PY-IRB.

Four hundred eighty non-carious human premolars extracted for orthodontic reasons and stored in $0.1 \%$ thymol solution at $4^{\circ} \mathrm{C}$ for a week, and then kept in physiologic saline at $5^{\circ} \mathrm{C}$ for less than 1 month before testing were used. To expose the mid-coronal dentine surface, teeth were horizontally

sectioned, perpendicular to their long axis, by using a slow-speed cutting instrument (Isocut ${ }^{\mathrm{TM}}$, Buehler, Lake Bluff, IL, USA). The occlusal dentine surface was grounded with 600 -grit silicon carbide paper under water running for 30s. The prepared teeth were randomly divided into 2 groups: control groups (120 teeth) and experimental groups (360 teeth). The prepared specimens of control groups would be finally stored in pure mineral oil. Otherwise, the prepared specimens in experimental groups would be finally stored in artificial saliva.

The teeth in control groups were further divided into 2 groups based on the adhesives used (OptiBond ${ }^{\circ} \mathrm{FL}$ or OptiBond ${ }^{\circ}$ Solo Plus ${ }^{\mathrm{TM}}$ ). The adhesives were applied according to the manufacturer's instructions. Two increments of a resin composite (Premise $^{\text {TM }}$, shade A2, Kerr corporation, CA, USA) were placed onto the flat bonded surfaces. Each increment of composite was light-activated for 20 seconds with a lightcuring unit with the intensity of $1200 \mathrm{~mW} / \mathrm{cm}^{2}$ (Bluephase LED curing lights, Ivoclar Vivadent Inc. Amherst, NY, USA). The specimens were further divided into 4 subgroups of 15 teeth for testing after 24 hours, 1 month, 3 months, and 1 year of storage in pure mineral oil (STE oil, Texas, USA).

The teeth in experimental groups were etched with phosphoric acid and divided into 3 groups based on dentine surfaces treatment as following with or without the application of chlorhexidine solution $(2 \%$ chlorhexidine digluconate solution, Bisco Inc., Schaumburg, IL, USA) for 60 seconds or $100 \mu \mathrm{M}$ rosmarinic acid solution in $5 \%$ ethanol (Sigma -Aldrich Co., St. Louis, MO, USA) for 10 seconds after acid etching. The treated specimens were further divided into 2 subgroups based on the adhesive used (OptiBond FL or OptiBond Solo Plus ${ }^{\mathrm{TM}}$ ). The adhesives were applied according to the manufacturer's instructions. The bonded specimens were then restored with the resin composite in the same manner as the control groups. The restored specimens were further divided into 4 subgroups of 15 teeth for testing after 24 hours, 1 month, 3 months, and 1 year of storage in artificial saliva (a mixture of $\mathrm{CaCl}_{2} 0.7 \mathrm{mmol} / \mathrm{L}, \mathrm{MgCl}_{2} .6 \mathrm{H}_{2} \mathrm{O} 0.02 \mathrm{mmol} / \mathrm{L}, \mathrm{KH}_{2} \mathrm{PO}_{4} 4.0 \mathrm{mmol} / \mathrm{L}$, $\mathrm{KCl} 30.0 \mathrm{mmol} / \mathrm{L}, \mathrm{NaN}_{3} 3.0 \mathrm{mmol} / \mathrm{L}$, HEPES buffer $20.0 \mathrm{mmol} / \mathrm{L}$ and distilled water).

Before storage, all specimens were vertically serial sectioned, perpendicular to the bonding surface, by using a slow-speed cutting instrument under water coolant. Two to three $1.2-\mathrm{mm}$-thick slabs were obtained from each tooth. The cut specimens from the twelve stored teeth in each group were subjected to micro-tensile testing, and the remaining 3 teeth were subjected to nanoleakage testing.

\section{Micro-tensile test}

After storage, the slabs were gently trimmed into hourglass specimens at the resin-tooth interfaces using cylindrical super-fine diamond burs (Superfine high speed flame diamond bur, Intensiv SA, Grancia, Switzerland) to approximately a $0.9-\mathrm{mm}$ neck width. This resulted in a cross-sectional area at

the bonded interface of approximately $1 \mathrm{~mm}^{2}$. The numbers of cut slabs including total numbers of cut slabs and number of pre-loading failure slabs (The numbers of specimens that were fractured at resindentine interfaces on specimen preparation before micro-tensile testing) in each group were recorded. Each specimen was then attached to a modified Bencor multi-T apparatus on a universal testing machine (Lloyd Instruments Ltd, Fareham Hanth, UK) with cyanoacrylate adhesive (Model Repair II blue, Dentsply-Sankin, Tokyo, Japan). A tensile load was applied at a crosshead speed of $0.5 \mathrm{~mm} / \mathrm{min}$ until failure occurred. The micro-tensile bond strength was expressed in megapascal $(\mathrm{MPa})$. All bond strengths data, including the pre-loading failure specimens, were calculated. The bond strength of $0 \mathrm{MPa}$ was recorded for the specimen with pre-loading failure.

After the strength test, the fractured specimens were examined under a scanning electron microscope (Model JSM 6610 LV, JEOL Company, Tokyo, Japan) at x100 magnification, and the failure locations were recorded in percentages of areas relating to the following categorization: adhesive failure, cohesive failure in resin, and cohesive failure in dentine.

The statistical analysis was performed using Levene's test, Komogorov Smirnoff test and a factorial analysis by variance at a 95\% level of confidence. Duncan's multiple comparison was used to determine the difference of means among groups. The failure modes were analysed using the Kruskal-Wallis test for non-parametrical data at $95 \%$ level of confidence.

\section{Nanoleakage test}

The remaining 3 teeth of each group were used to investigate nanoleakage under the SEM. After different periods of storage, the resin-dentine slabs were removed from the storage solution, washed in tab water for 5 minutes and carefully dried. The specimens except for the area of $1 \mathrm{~mm}$ around the rein-dentine interfaces were coated with two layer of nail varnish and were then rehydrated in distilled water for $10 \mathrm{~min}$ before being immersed in the silver nitrate solution $(50 \%$ $\mathrm{w} / \mathrm{v}$ ) at $\mathrm{pH} 3.4$ for 24 hours in a dark room at room temperature, rinsed thoroughly with distilled water and immersed in photo developing solution for 8 hours. Finally, the specimens were soaked in fixer solution for 2 minutes.

The silver-stained specimens were embedded in epoxy resin and left for 24 hours until the epoxy resin was completely set. The embedded specimens were ground with a series of silicon carbide paper ranging from 600-grit to 4000-grit under running water and finally polished with diamond paste in sequent size to a size of $\mu 0 \mathrm{~m}$. The polished specimens were examined for nanoleakage under the SEM with backscattered electron images at magnifications of 1000x.

\section{Results}

In an attempt to delay enzymatic degradation, the use of chlorhexidine and rosmarinic acid solutions was investigated in this 
study. All specimens were kept in artificial saliva for activation of MMPs as experimental groups or in pure mineral oil for inactivation of MMPs as control group to prevent the enzymatic degradation. The significant factors were adhesive materials, surface treatment/storage conditions and storage times (Table 1).

Statistical analysis using three-way ANOVA revealed significant effects of adhesive materials, surface treatment/storage conditions and storage times with $p=0.80, p<0.01$ and $p<0.01$, respectively. An interaction between factors was found between surface treatment/ storage conditions and storage times $(p<0.01)$.

The means and standard deviations of micro-tensile bond strengths of resin composite restoration bonded with either OptiBond ${ }^{\circ}$ FL or OptiBond Solo Plus ${ }^{\mathrm{TM}}$ are showed in Table 2.

Comparing the control and experimental groups without additional surface treatment for both dental adhesives, no significant difference in the bond strength values was found ( $p>0.05)$ after 24 hours of storage in pure mineral oil or artificial saliva. Conversely, after 3 months, 6 months and 1 year of storage in artificial saliva, a significant decrease in bond strength $(p<0.05)$ was observed in both groups of dental adhesives compared with those that had been stored in pure mineral oil. Additionally, low bond strength values with prominently preloading failure were found after 1 year of storage ( 24 of 28 specimens of Optibond Solo kept in artificial saliva group and 24 of 29 specimens of Optibond FL kept in artificial saliva group). The means \pm standard deviations in bond strength of the Optibond FL and Optibond Solo Plus specimens that were kept in artificial saliva for 1 year were $3.91 \pm$ 9.20 with $82.76 \%$ pre-loading failure and $3.10 \pm 9.20$ with $85.71 \%$ preloading failure, respectively. The bond strength without pre-loading failure was sustained in the control groups for all storage times up to 1 year. No significant differences were found among the storage times in either of the tested adhesive groups that were kept in pure mineral oil.
With the application of either $2 \%$ chlorhexidine digluconate solution or $100 \mu \mathrm{M}$ rosmarinic acid solution, no significant difference in bond strengths were found ( $p>0.05)$ among the groups of both adhesives compared with the control groups and the groups without surface treatment after 24 hours of storage. After 3 months of storage, the group without surface treatment for both of Optibond FL and Optibond Solo Plus that was kept in artificial saliva exhibited a significant decrease $(p<0.05)$ in bond strength, whereas groups with dentine treated with either $2 \%$ chlorhexidine digluconate solution or $100 \mu \mathrm{M}$ rosmarinic acid solution showed no significant difference in bond strength $(p>0.05)$ compared with both the 24 hours groups and the control groups at 24 hours and 3 months.

After 6 months, the groups kept in artificial saliva had bond strength values that were significantly decreased compared those observed after 24 hours of storage. After 6 months of storage, significantly lower bond strength was found in the Optibond Solo group that was kept in saliva, the Optobond FL group with chlorhexidine gluconate solution treatment that was kept in saliva, compared with the control groups that were kept in natural mineral oil. Nevertheless, no significant differences were observed $(p>0.05)$ in the reduction in bond strength in the groups treated with $2 \%$ chlorhexidine digluconate solution or $100 \mu$ $\mathrm{M}$ rosmarinic acid solution or the groups without surface treatment, all of which were kept in artificial saliva after 6 months of storage.

After 1 year of storage, the control groups that were kept in mineral oil demonstrated sustainability in their bond strength without any difference from the bond strength at $24 \mathrm{hrs}$. A gradual decrease in bond strength was observed in the groups that had been kept in artificial saliva. The bond strength values were significantly decreased compared with the values found after 24 hours of storage. Comparing among groups after 1 year of storage, significantly lower bond strength and highly pre-loading failure were found in the Optibond FL and

Table 1. The adhesive systems and composite resin used in this study.

\begin{tabular}{|c|c|c|c|c|}
\hline Material & Composition & Instruction & Lot No. & Manufacturer \\
\hline 1. OptiBond ${ }^{\circledast}$ FL & $\begin{array}{l}\text { Etchant: } 37.5 \% \text { phosphoric acid, } \\
\text { Silica thickener. } \\
\text { Primer: HEMA, GPDM, PAMM, } \\
\text { Ethanol, Water, } \\
\text { Photoinitiator. } \\
\text { Adhesive: TEGDMA, UDMA, } \\
\text { GPDM, HEMA, Bis-GMA, } 48 \% \\
0.6 \text { barium glass fillers, Disodium } \\
\text { hexafluorosilicate, } \\
\text { Photoinitiator. }\end{array}$ & $\begin{array}{l}\text { 1.Place etchant on dentin/enamel } \\
\text { for } 15 \text { seconds Rinse with water } \\
\text { for approximately } 15 \text { seconds, } \\
\text { and gently air dry for a few } \\
\text { 2. Apply primer with a light } \\
\text { scrubbing motion for } 15 \text { seconds, } \\
\text { gently air dry for approximately } \\
5 \text { seconds. } \\
\text { 3. Apply adhesive with a light } \\
\text { scrubbing motion for } 15 \text { seconds, } \\
\text { blow to margin or to thin } \\
\text { 4. Light cure for } 10 \mathrm{sec}\end{array}$ & $\begin{array}{l}\text { N } 3327650 \\
\text { N } 3304442 \\
\text { N } 3304440\end{array}$ & $\begin{array}{l}\text { Kerr corporation, } \\
\text { Orange, CA, USA }\end{array}$ \\
\hline $\begin{array}{l}\text { 2. OptiBond } \\
\text { Solo PlusTM }\end{array}$ & $\begin{array}{l}\text { Etchant: } 37.5 \% \text { phosphoric acid, } \\
\text { Silica thickener. } \\
\text { Primer/adhesive: Bis-GMA, } \\
\text { GDM, HEMA, GPDM, Ethanol, } \\
15 \% 0.4 \mu \mathrm{m} \text { barium glass fillers, } \\
\text { photoinitiator }\end{array}$ & $\begin{array}{l}\text { 1.Etch enamel and dentin for } 15 \\
\text { seconds } \\
\text { 2. Rinse thoroughly for } \\
\text { approximately } 15 \text { seconds } \\
\text { 3. Dry lightly (do not desiccate). } \\
\text { 4. Apply adhesive to enamel/dentin } \\
\text { surface for } 15 \\
\text { 5. seconds, using light brushing } \\
\text { motion } \\
\text { 6. Air thin for } 3 \text { seconds. } \\
\text { 7. Light cure for } 10 \text { seconds }\end{array}$ & $\begin{array}{l}\text { N } 3327650 \\
\text { N } 3320225\end{array}$ & $\begin{array}{l}\text { Kerr corporation, } \\
\text { Orange, CA, USA }\end{array}$ \\
\hline $\begin{array}{l}\text { Premise }^{\mathrm{TM}} \text { resin } \\
\text { composite }\end{array}$ & $\begin{array}{l}\text { Matrix: Bis-EMA, TEGDMA, } \\
\text { Initiators, Stabilizers } \\
\text { Filler: } 69 \text { vol } \% \text { prepolymerized } \\
\text { filler }(30 \text { to } 50 \mathrm{~mm}) \text {, Barium glass } \\
(0.4 \mathrm{~mm}) \text {, and Silica } \\
\text { nanoparticles }(0.02 \mathrm{~mm})\end{array}$ & $\begin{array}{l}\text { 1. Increments filling with no more } \\
\text { than } 2.5 \mathrm{~mm} \text { at a time } \\
\text { 2. Light cure each increment for } 20 \\
\text { seconds }\end{array}$ & 3156753 & $\begin{array}{l}\text { Kerr corporation, } \\
\text { Orange, CA, USA }\end{array}$ \\
\hline
\end{tabular}

Abbreviations: HEMA: Hydroxyethyl methacrylate; GPDM; Glycero-phosphate dimethacrylate; PAMM: Phthalic acid monoethyl methacrylate; TEGDMA: Triethylene glycol dimethacrylate; UDMA: Diurethane dimethacrylate; Bis-GMA: Bisphenol A-glycidyl methacrylate 2,2-bis[4-(2-hydroxy-3-methacryloxypropoxy)phenyl]propane; GDM: Glyceroldimethacrylate; Bis-EMA: Ethoxylated bisphenol A glycol dimethacrylate 
Table 2. The means \pm standard deviations of bond strengths with statistical analysis.

\begin{tabular}{|c|c|c|c|c|c|c|c|c|c|}
\hline \multirow{3}{*}{$\begin{array}{c}\text { Groups } \\
\text { Solo-saliva-1year }\end{array}$} & \multicolumn{2}{|c|}{ Number of cut slabs } & \multirow{2}{*}{\multicolumn{7}{|c|}{$\begin{array}{c}\text { Bond strengths } \\
\text { (mean } \pm \text { standard deviation) }\end{array}$}} \\
\hline & \multirow{2}{*}{$\begin{array}{c}\begin{array}{c}\text { Total } \\
\text { numbers }\end{array} \\
28\end{array}$} & \multirow{2}{*}{$\begin{array}{c}\begin{array}{c}\text { Pre-loading } \\
\text { failure }\end{array} \\
24 \\
\end{array}$} & & & & & & & \\
\hline & & & $3.10 \pm 8.22$ & & & & & & \\
\hline FL-saliva-1year & 29 & 24 & $3.91 \pm 9.20$ & & & & & & \\
\hline Solo-CHX-1year & 20 & 0 & & $22.85 \pm 11.72$ & & & & & \\
\hline FL-saliva-6months & 28 & 0 & & $26.46 \pm 6.39$ & $26.46 \pm 6.39$ & & & & \\
\hline FL-CHX-1year & 23 & 0 & & & $27.82 \pm 11.54$ & $27.82 \pm 11.54$ & & & \\
\hline FL-rosmaric-1year & 24 & 0 & & & $28.04 \pm 9.09$ & $28.04 \pm 9.09$ & & & \\
\hline Solo-rosmaric-1year & 24 & 0 & & & $28.98 \pm 7.68$ & $28.98 \pm 7.68$ & & & \\
\hline FL-CHX-6months & 33 & 0 & & & $29.33 \pm 6.66$ & $29.33 \pm 6.66$ & & & \\
\hline FL-saliva-3months & 31 & 0 & & & $29.45 \pm 8.12$ & $29.45 \pm 8.12$ & & & \\
\hline Solo-saliva-6months & 30 & 0 & & & $30.54 \pm 8.05$ & $30.54 \pm 8.05$ & & & \\
\hline Solo-rosmary-6months & 29 & 0 & & & $31.37 \pm 10.24$ & $31.37 \pm 10.24$ & $31.37 \pm 10.24$ & & \\
\hline Solo-saliva-3months & 30 & 0 & & & & $32.13 \pm 7.32$ & $32.13 \pm 7.32$ & $32.13 \pm 7.32$ & \\
\hline FL-rosmary-6months & 26 & 0 & & & & $32.79 \pm 7.37$ & $32.79 \pm 7.37$ & $32.79 \pm 7.37$ & \\
\hline Solo-CHX-6months & 27 & 0 & & & & $32.83 \pm 6.82$ & $32.83 \pm 6.82$ & $32.83 \pm 6.82$ & \\
\hline FL-oil-6months & 29 & 0 & & & & & $35.73 \pm 5.77$ & $35.73 \pm 5.77$ & $35.73 \pm 5.77$ \\
\hline Solo-rosmary-24hrs & 20 & 0 & & & & & $36.00 \pm 8.04$ & $36.00 \pm 8.04$ & $36.00 \pm 8.04$ \\
\hline FL-oil-3months & 27 & 0 & & & & & $36.46 \pm 7.66$ & $36.46 \pm 7.66$ & $36.46 \pm 7.66$ \\
\hline Solo-oil-6months & 27 & 0 & & & & & & $36.87 \pm 6.83$ & $36.87 \pm 6.83$ \\
\hline FL-saliva-24hrs & 20 & 0 & & & & & & $37.27 \pm 8.45$ & $37.27 \pm 8.45$ \\
\hline Solo-CHX-24hrs & 23 & 0 & & & & & & & $38.42 \pm 8.04$ \\
\hline FL-rosmary-3months & 27 & 0 & & & & & & & $38.43 \pm 10.12$ \\
\hline FL-CHX-24hrs & 22 & 0 & & & & & & & $38.46 \pm 7.82$ \\
\hline Solo-oil-1year & 25 & 0 & & & & & & & $39.03 \pm 10.55$ \\
\hline Solo-rosmary-3months & 27 & 0 & & & & & & & $39.43 \pm 10.12$ \\
\hline FL-oil-1year & 23 & 0 & & & & & & & $39.60 \pm 9.31$ \\
\hline Solo-saliva-24hrs & 24 & 0 & & & & & & & $39.60 \pm 7.50$ \\
\hline FL-oil-24hrs & 23 & 0 & & & & & & & $39.87 \pm 7.00$ \\
\hline Solo-oil-3months & 31 & 0 & & & & & & & $39.95 \pm 9.86$ \\
\hline Solo-oil-24hrs & 26 & 0 & & & & & & & $40.63 \pm 6.68$ \\
\hline Solo-CHX-3months & 31 & 0 & & & & & & & $40.75 \pm 7.12$ \\
\hline FL-CHX-3months & 29 & 0 & & & & & & & $41.26 \pm 5.51$ \\
\hline FL-rosmary-24hrs & 23 & 0 & & & & & & & $41.27 \pm 6.76$ \\
\hline Significance by Du & n's multiple c & arison & 0.723 & 0.118 & 0.069 & 0.069 & 0.056 & 0.057 & 0.053 \\
\hline
\end{tabular}

(FL: Optibond FL; Solo: Optibond Solo Plus; oil: Natural mineral oil; saliva: Artificial saliva; CHX: 2\% chlorhexidine digluconate solution; rosmary: 100 $\mu$ M rosmarinic acid solution; 24 hrs 24 hours storage time; 3 months: 3 months storage time; 6months: 6 months storage time; 1year: 1 year storage time)

Optobond Solo Plus without surface treatment groups that were kept in saliva. Furthermore, there was a reduction in bond strength with the application of either $2 \%$ chlorhexidine digluconate solution or $100 \mu \mathrm{M}$ rosmarinic acid solution dentine treatment compared with the control groups $(p<0.05)$. Treatment with $2 \%$ chlorhexidine digluconate and Optibond Solo Plus was found to be significantly less effective in maintaining the bond strength compared with $2 \%$ chlorhexidine digluconate with Optibond FL, which, in turn, was less effective than the application of $100 \mu \mathrm{M}$ rosmarinic acid solution with both adhesives.

The application of either rosmarinic acid solution or $2 \%$ chlorhexidine digluconate demonstrated significantly higher bond strength at 1 year for both OptiBond $\mathrm{FL}^{\circ}$ and Optibond Solo Plus ${ }^{\mathrm{TM}}$ compared with the group that did not receive any dentine treatment.

The means of percentage of failure mode distribution for both OptiBond ${ }^{\circ} \mathrm{FL}$ and OptiBond Solo Plus ${ }^{\mathrm{TM}}$ are presented in Figure 1. For all groups, adhesive failures were prominently observed at the interfaces of fractured specimens.

Statistical analysis was performed using Kruskal-Wallis for nonparametrical analysis. It demonstrated no patterns of differences in the fractured modes among the tested groups.
The nanoleakage test under SEM was used to investigate the enzymatic degradation of the resin-dentine interfaces in this study. There was no silver penetration into resin-dentine interfaces for any observation of the specimens bonded with either Optibond FL' (Figure 2) or Optibond ${ }^{\circ}$ Solo Plus ${ }^{\mathrm{TM}}$ (Figure 3) that were kept in pure mineral oil (control groups).

The various degrees of silver deposits at the resin-dentine interfaces were found in the groups that were kept in artificial saliva. However, the deposition of silver particles at the resin-dentine interfaces including at the bottom of hybrid layer related to the discrepancy between the depth of acid etching and resin infiltration could not be observed in the groups that were kept for 24 hours.

For the groups bonded with Optibond FL (Figure 2), a gradual increase in the silver deposits was found for up to 1 year of storage time. In the groups without dentine surface treatment, the adhesives interfacial showed silver deposits (white arrows) as silver nanoleakage within the hybrid layer at 3 months. The amount of silver deposits within the hybrid layer accumulated greatly in the 6-month storage and formed clear deposition at 1 year. With the application of $2 \%$ chlorhexidine digluconate and $100 \mu \mathrm{M}$ rosmarinic acid solution, the 


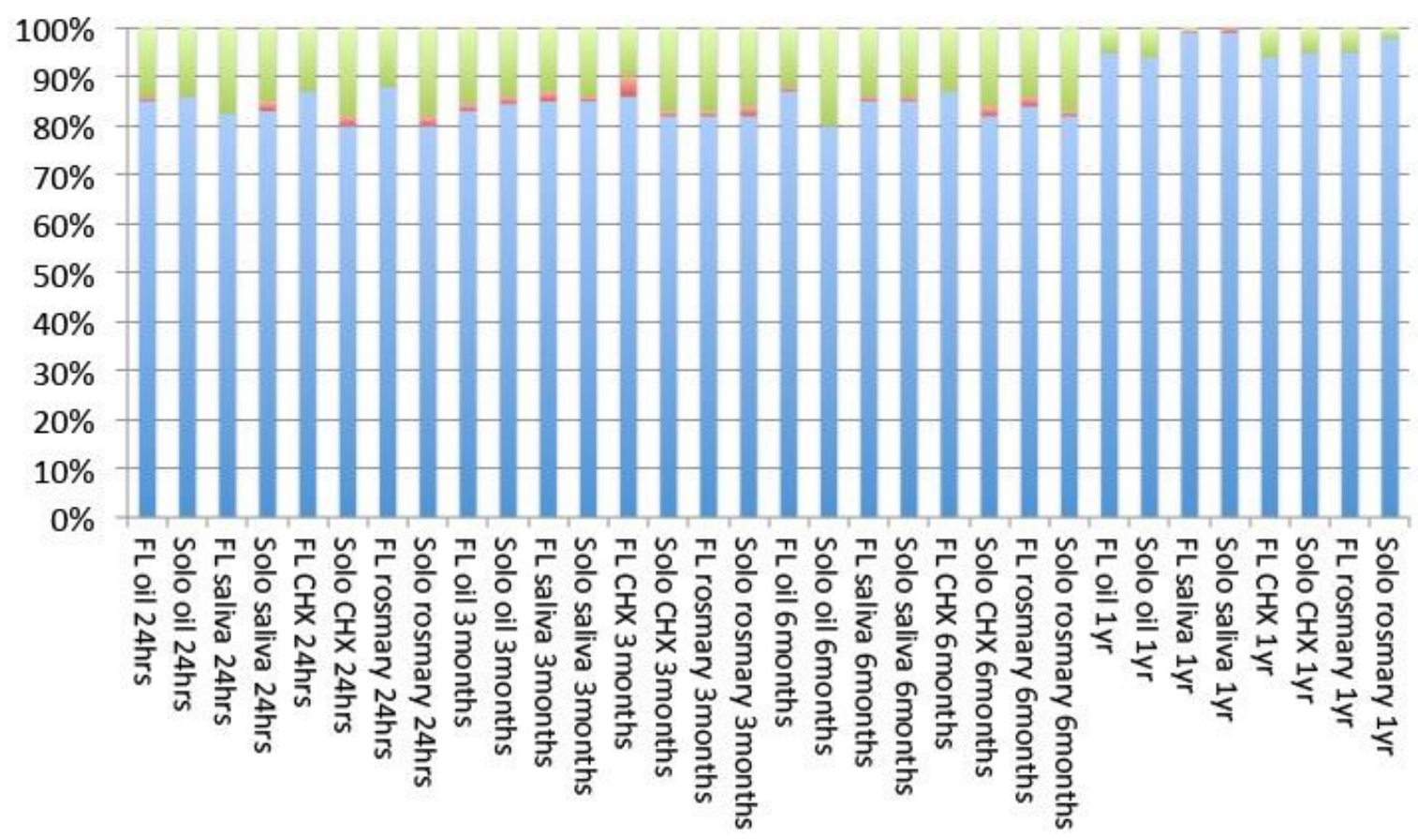

Adhesive failure $\quad$ Cohesive failure in dentine Cohesive failure in resin

Figure 1. Percentage of failure mode patterns of tested groups.

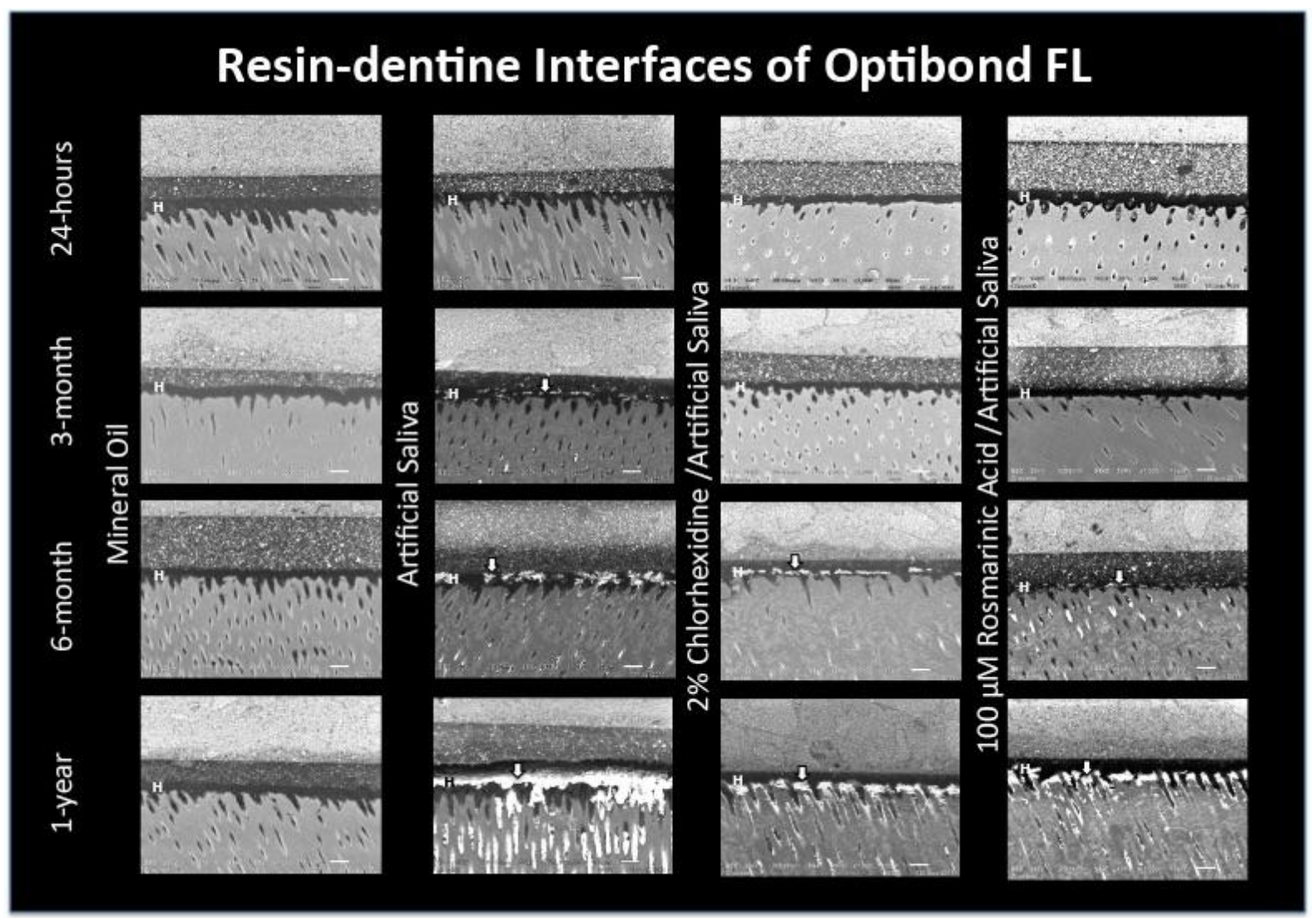

Figure 2. SEM images (1000x) at resin-dentine interfaces of Optibond FL adhesives. (The structure at "H" represents the hybrid layers, and the structures at the white arrows represents the nanoleakage). 


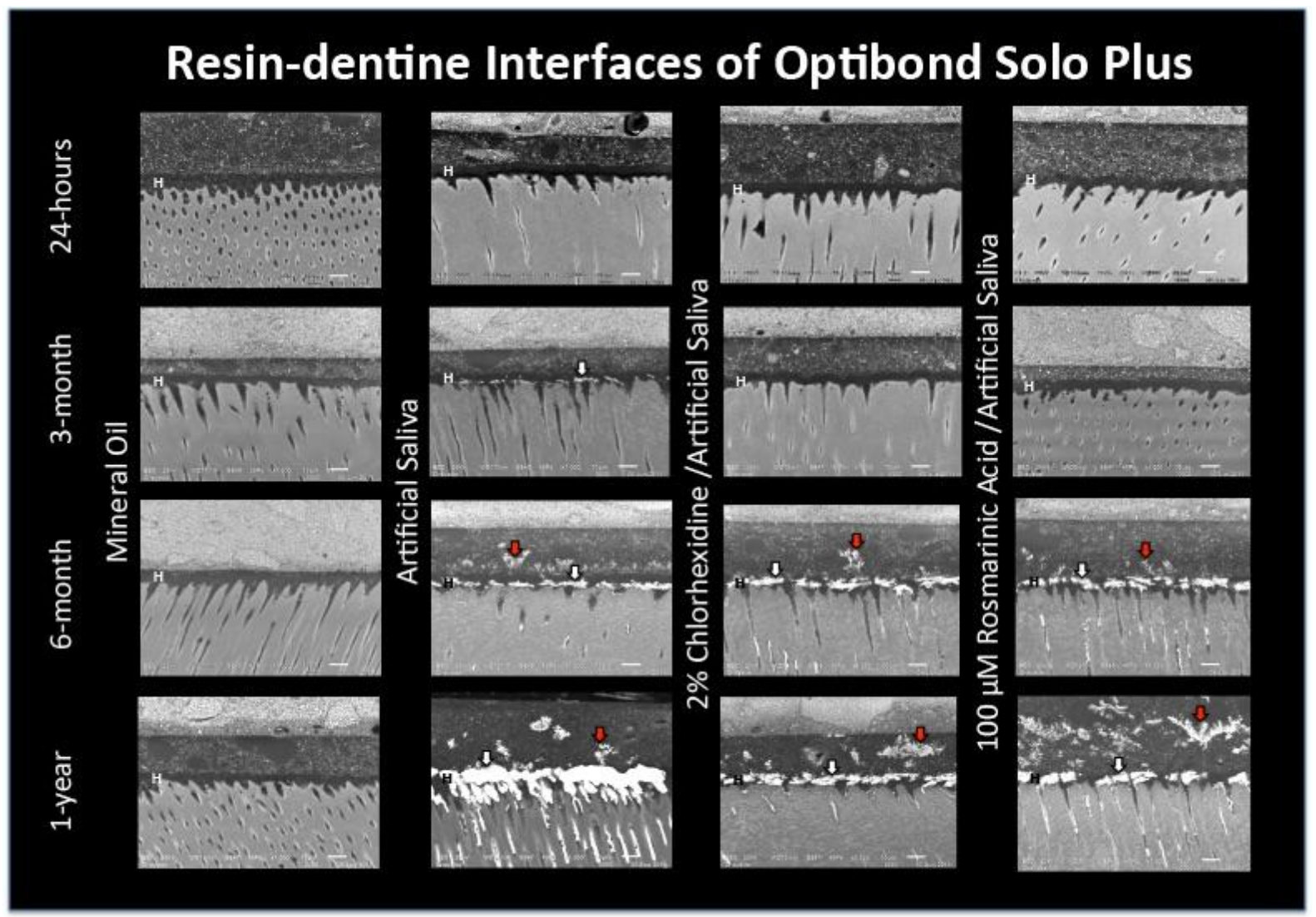

Figure 3. SEM images (1000x) at resin-dentine interfaces of Optibond Solo Plus adhesives. (The structure at " $H$ " represents the hybrid layers, the structures at the white arrows represents the nanoleakage and the structures at the red arrows represents the water tree nanoleakage)

deposits of silver particles were observed at 6 months and increased by 1 year. The nanoleakage that occurred at resin-dentine interfaces started with deposits at the bottom of the hybrid layer.

For the groups bonded with Optibond Solo Plus (Figure 3), there was a gradual increase in the silver deposition up to 1 year of storage time. In the groups without dentine surface treatment, the resin-dentine interfaces showed silver deposits (white arrows) as silver nanoleakage within the hybrid layer at 3 months. The silver deposits within the hybrid layer had a greater accumulation after 6 months of storage and obviously greater deposits at 1 year. The water tree nanoleakage (red arrows) of silver staining within adhesive layers of Optibond Solo Plus was observed at 6 months. These deposits were obvious at 1 year. With the application of $2 \%$ chlorhexidine digluconate and $100 \mu \mathrm{M}$ rosmarinic acid solution, the deposits of silver particles were observed at 6 months and had increased at 1 year. The nanoleakage that occurred at the resin-dentine interfaces also started with deposits at the bottom of the hybrid layer.

\section{Discussion}

In the present study, the storage times affected the bond strength of etch-and-rinse adhesives on dentine that had been treated with either three- or two-step etch-and-rinse adhesives. Because the degradation of resin-dentine bond interfaces that were kept in artificial saliva was significantly degraded over times and a higher nanoleakage expression was found, a comparison with storage in pure mineral oil demonstrated a dependence on storage time. Thus, the null hypothesis was rejected.

The pattern of nanoleakage at the bottom of hybrid layers with etch-and-rinse adhesive that was related to the discrepancy between the depth of acid etching and resin infiltration [5,10,11] within 24 hours testing could not be observed in this study. The complete penetration of these adhesives to any depth of demineralized dentine was observed for all groups at 24 hours of storage. Thus, the complete polymerization of adhesives within hybrid layer especially at the bottom of hybrid layer might be expected from the incorporation of initiator system in both primer and adhesive for OptiBond ${ }^{\circ} \mathrm{FL}$ and OptiBond Solo Plus ${ }^{\mathrm{TM}}$ (Table 1). This may cause complete polymerization that make the hybrid layer tolerate to initial degradation by decreasing of permeability that might cause reducing monomer elution $[19,20]$ at initial storage. Therefore, the depositions of silver particles in various degrees were observed after 3 months of storage for all experimental groups with times dependence.

Storage in pure mineral oil could prevent the water-dependence of the enzymatic and hydrolytic degradation mechanisms that occurred at the resin-dentine bond interfaces, as confirmed by Sanabe and co-workers [21]. Their study showed that no increase in the exposed collagen zone could be observed in specimens that had been kept in mineral oil compared with those kept in water for up to 1 year. Because the activation of MMPs depends on the presence of water and calcium and zinc ions, the enzymes were not stimulated to be active when the specimens were immersed in pure mineral oil [22].

Conversely, it was found that the bond strength was reduced in groups without dentine treatment using either three- or two-step etch-and-rinse adhesives that were aging in artificial saliva. The bond strength was decreased significantly $(p<0.05)$ after 3 months, 6 months and 1 year of storage time. The interfacial adhesives of the 3 -month storage group showed silver deposits as nanoleakage within the hybrid layer, starting at the bottom of the hybrid layer. 
The number of silver deposits within the hybrid layer accumulated greatly in the 6-month storage groups and were obvious in the 1-year storage groups, which indicated that the resin-dentine interfaces degraded over time. The bond degradation of the etch-and-rinse adhesives resulted from the degradation of the unprotected collagen matrix, which occurred where the resin adhesives in the interfibrillar space washydrolysis, which was caused by theleaching of unpolymerized resin within the hybrid layer [8]. Thus, the water content was increased in the bonded interfaces, which was detrimental to the longevity of the resin-dentine bond. The findings obtained in this therefore study support the action of host-derived matrix metalloproteinase within the dentine matrix that could degrade the collagen matrices. Because MMPs are hydrolases, the active MMPs hydrolyze the peptide bonds in collagen, which results in the degradation of the resin-dentine interfaces within the hybrid layer in the presence of water in artificial saliva [23].

Nevertheless, after 6 months of storage, the groups of dentine surfaces that were treated with Optibond Solo Plus and stored in artificial saliva showed silver deposited within the channel in the adhesive layer demonstrated as the water tree nanoleakage. This was not found in the groups of dentine surfaces that were treated with Optibond FL. The use of phosphoric acid in etch-and-rinse adhesive systems has been reported to increase dentine permeability in terms of both the fluid flux and the hydraulic conductance $[24,25]$. Since two-step etchand-rinse adhesives are more hydrophilic than three-step etch-andrinse adhesives, the use of the two-step adhesives are more susceptible to the high degree of wetness on dentine that is caused by the totaletching procedure [26]. Because the simplified two-step etch-and-rinse adhesives combined hydrophilic and ionic resin monomers into the bond, which resulted in higher percentages of hydrophilic monomers, the hybrid layer was formed after polymerization occurred on the semi-permeable membranes. This permitted water to move throughout the resin-dentine bonded interface as water tree nanoleakage, and the interface then acted as a potential site for the hydrolytic degradation of the resin-dentine bond [11].

With the more hydrophobicity of three-step etch-and-rinse adhesives [27], the use of these adhesives did not cause water tree formation within the adhesive layers of the three-step adhesives compared with the two-step adhesives for the specimens that were kept in artificial saliva for 6 months and 1 year. The water tree was proposed to occur by the poor polymerization of hydrophilic resin that was vulnerable to degradation [28].

The application of $2 \%$ chlorhexidine digluconate or $100 \mu \mathrm{M}$ rosmarinic acid solution as a dentine surface treatment could have decelerated the degradation of the resin-dentine interfaces at 3 months of aging, which showed no significant reduction $(p>0.05)$ in bond strength and no difference in the nanoleakage patterns compared with the 24-hour groups. Nevertheless, a significant reduction $(p<0.05)$ in bond strength was found at 6 months of aging, and silver deposits occurred within the hybrid layer. These observations were results of the degradation of the resin-dentine interfaces. These results do not support the acceptance of the null hypothesis. The reduced bond strength and the deposition of silver staining were both dependent on storage time.

The $2 \%$ chlorhexidine digluconate is featured as a strong base with cationic properties. It results from a cationic-anionic reaction with negatively charged molecules of the dentine matrix, such as the carboxyl $(-\mathrm{COOH})$ or hydroxyl $(-\mathrm{OH})$ domains, via electrostatic attraction forces [29]. The effectiveness of chlorhexidine decelerated the collagen matrices' degradation because of its zinc ${ }^{2+}$ cation- chelating property [30]. By preventing the binding of ions such as zinc or calcium to the MMPs, which inhibited their catalytic activity causes deceleration of the collagen matrices' degradation. Moreover, the possible coordination of the hydroxyl group of HEMA, which is contained in resin monomers with the zinc ${ }^{2+}$ cation that present in the catalytic domain of MMPs, was suggested to be the main inhibitory mechanism [31]. It caused the resin adhesives to encapsulate the MMPs and occupied their catalytic domain sites.

However, the chlorhexidine treatment of acid-etched dentine failed to prevent the collagen degradation of the hybrid layer for up to 6 months after the initial treatment, which is consistent with the recent finding of Sadek FT and co-workers [32]. Those authors showed that the chlorhexidine pretreatment of etch-and-rinse adhesive bonded to dentine failed to prevent hybrid layer degradation for up to 9 months of aging. Although the application of chlorhexidine with a etch-andrinse technique on etched dentine surfaces prevented the collagen matrices from collapsing, it caused incomplete water removal from the interfibrillar collagen matrix rendered to the chlorhexidine and was dissolved by water that functioned as the desorption medium [33]. The study of Kim and co-workers [33] showed that water is effective in debinding chlorhexidine from the dentine matrix based on its electrostatic binding characteristics because water qualifies as the strongest known H-bonding solvent. Water can form H-bonds with collagen molecules rather than with chlorhexidine, thereby causing debinding and leaching out of the hybrid layer. Thus, at 6 months of aging, the effectiveness of chlorhexidine as an MMP inhibitor was decreased, which resulted in a reduction of its MMP-inhibitory effect on collagen-bound MMPs. Chlorhexidine could not protect the resindentine bond from water degradation. Related SEM images of resindentine interfaces in both three- and two-step etch-and-rinse adhesives revealed silver uptake from the degradation of the hybrid layer.

The $100 \mu \mathrm{M}$ rosmarinic acid solution was used as a MMP-inhibitor to prevent resin-dentine bond degradation and had the advantages of its antioxidant activity and short application time. The application time of 10 seconds is less than the 60 seconds that are required for the application of $2 \%$ chlorhexidine digluconate. Prasansuttiporn and coworkers found that the application of rosmarinic acid solution for 5 or 10 seconds exhibited a significant reversal effect on the improved bond strength of NaOCl-treated dentine [18]. Since, Xu Y and coworkers [34] demonstrated that rosmarinic acid could suppress the activities of MMP-2 and MMP-9 and was anti-metastatic for cancer cells, the rosmarinic acid might be applied in the attempt to prevent the enzymatic degradation of collagen and improve the durability of the resin dentine bond. The present study showed that rosmarinic acid could prevent the degradation of the resin-dentine bond for up to 3 months of aging.

The effectiveness of rosmarinic acid to improve durability of resindentine bond is its antioxidant characteristics [35]. The antioxidant activity of rosmarinic acid is due to the presence of four phenolic hydrogens $(-\mathrm{OH})$. These could contribute to the control of free radical oxidation and allow rosmarinic acid to act as a chain-breaking antioxidant because it scavenges reactive radicals from electron delocalization in the aromatic ring such that the reactive radical is replaced with one of limited reactivity [36]. Thus, the inhibition of the MMPs' effect on rosmarinic acid could, as a result, scavenge 2,2-Diphenyl-1-Picrylhydrazyl (DPPH) radicals, alkoxyl radicals (RO) and lipid peroxyl radicals (ROO) that have the ability to suppress TNFa-induced intracellular reactive oxygen species (ROS) production. 
MMPs can be induced by TNF- $\alpha$. The inhibition of TNF-ais consistent with the inhibition of MMP activation and expression [37].

After a 6-month period of aging in artificial saliva, the effectiveness of rosmarinic acid in preventing the resin-dentine bond was decreased, as observed in the SEM images of the resin-dentine interfaces following the application of both three- and two-step etch-and-rinse adhesives that reveal silver uptake from the degradation of the hybrid layer. The leakage patterns of silver nitrate deposition in the resin-dentine interfaces could enlarge the nanoleakage channels, which would lead to water sorption and would accelerate the hybrid layer degradation. There was speculation that the same explanation could apply to chlorhexidine. Water qualifies as the strongest known hydrogenbonding solvents because it can form hydrogen bond with collagen molecules rather than rosmarinic acid, thereby causing debinding and leaching out of the hybrid layer. Thus, progressive water sorption into the hybrid layer causes the disorganization of collagen fibrils and the elution of resin from the interfibrillar space within the hybrid layer, which leads to the further deterioration of the longevity of the resindentine bond [5].

It has been proposed that $2 \%$ chlorhexidine digluconate has the ability to inhibit MMPs activity via its $\mathrm{Zn}^{2+}$ cation-chelating property [30]. In addition, $100 \mu \mathrm{M}$ rosmarinic acid exerts an inhibitory effect because of its antioxidant activity in conjunction with the suppression of TNF- $\alpha$-induced intracellular reactive oxygen species production [37]. However, after aging specimens in artificial saliva for 6 months, there was a decrease in the dentine bond strength. These specimens had received applications of either three- or two-step etch-andrinse adhesives on the dentine surface and were treated with either chlorhexidine or rosmarinic acid solution. They were not significantly $(p>0.05)$ different from the specimens that did not receive dentine treatment. Thus, the difference in the bond strength of the dentine surface treated with either chlorhexidine or rosmarinic acid solution and the dentine surfaces without additional treatment was found to be significant at 1 year. The null hypothesis was rejected.

A gradual decrease in bond strength was observed even in the groups that had been treated with chlorhexidine or rosmarinic acid solution and stored for up to 1 year. Although a MMP inhibitor was used to prevent resin-dentine bond degradation, the degradation still occurred when the specimens were immersed in artificial saliva due to water sorption into the interfaces. This initiated the degradation that resulted from the hydrolysis of collagen and/or resin adhesives. The limitation of an effective time interval could be of concern because it affects the performance of the action of MMP inhibitors.

\section{Conclusions}

Within the limitations of this study, the following can be concluded:

1. The bond strength of the resin-dentine bond of Optibond FL and Optibond Solo Plus ${ }^{\mathrm{TM}}$ kept in artificial saliva significantly decreased over time, and the nanoleakage expression increased compared with those that were stored in pure mineral oil for 6 months.

2. The bond strength of the resin-dentine bond with application of either $2 \%$ chlorhexidine digluconate solution or $100 \mu \mathrm{M}$ rosmarinic acid solution was significantly decreased, and a higher nanoleakage expression was found at 6 months of storage time.

3. The effectiveness of MMP inhibitors in preserving the integrity of the hybrid layer and the dentine bond strength was time-dependent. Thus, the limitation of an effective interval should be considered.

\section{References}

1. Watanabe I, Nakabayashi N (1993) Bonding durability of photocured phenyl-P in TEGDMA to smear layer-retained bovine dentin. Quintessence Int 24: 335-342. [Crossref]

2. Burrow MF1, Satoh M, Tagami J (1996) Dentin bond durability after three years using a dentin bonding agent with and without priming. Dent Mater 12: 302-307. [Crossref]

3. Breschi L, Mazzoni A, Ruggeri A, Cadenaro M, Di Lenarda R, et al. (2008) Dental adhesion review: aging and stability of the bonded interface. Dent Mater 24: 90-101. [Crossref]

4. Sano H, Yoshikawa T, Pereira PN, Kanemura N, Morigami M, et al. (1999) Long-term durability of dentin bonds made with a self-etching primer, in vivo. $J$ Dent Res 78: 906-911. [Crossref]

5. Hashimoto M, Ohno H, Sano H, Kaga M, Oguchi H (2003) In vitro degradation of resin-dentin bonds analysed by microtensile bond test, scanning and transmission electron microscopy. Biomater 24: 3795-3803.

6. De Munck J, Van Meerbeek B, Yoshida Y, Inoue S, Vargas M, et al. (2003) Four-year water degradation of total-etch adhesives bonded to dentin. J Dent Res 82: 136-140. [Crossref]

7. Abdalla AI, Feilzer AJ (2008) Four-year water degradation of a total-etch and two selfetching adhesives bonded to dentin. J Dent 36: 611-617. [Crossref]

8. Hashimoto M, Fujita S, Nagano F, Ohno H, Endo K (2010) Ten-years degradation of resin-dentin bonds. Eur J Oral Sci 118: 404-410. [Crossref]

9. Hashimoto M, Ohno H, Kaga M, Endo K, Sano H, et al. (2000) In vivo degradation of resin-dentin bonds in humans over 1 to 3 years. J Dent Res 79: 1385-1391. [Crossref]

10. Wang Y, Spencer P (2002) Quantifying adhesive penetration in adhesive/dentin interface using confocal Raman microspectroscopy. J Biomed Mater Res 59: 46-55. [Crossref]

11. Pashley DH, Tay FR, Breschi L, Tjäderhane L, Carvalho RM, et al. (2011) State of the art etch-and-rinse adhesives. Dent Mater 27: 1-16. [Crossref]

12. Sano H, Takatsu T, Ciucchi B, Horner JA, Matthews WG, et al. (1995) Nanoleakage leakage within the hybrid layer. Oper Dent 20: 18-25. [Crossref]

13. Pashley DH, Tay FR, Yiu C, Hashimoto M, Breschi L, et al. (2004) Collagen degradation by host-derived enzymes during aging. J Dent Res 83: 216-221. [Crossref]

14. Sano H (2006) Microtensile testing, nanoleakage, and biodegradation of resin-dentin bonds. J Dent Res 85: 11-14. [Crossref]

15. Gendron R, Grenier D, Sorsa T, Mayrand D (1999) Inhibition of the activities of matrix metalloproteinases 2, 8, and 9 by chlorhexidine. Clin Diagn Lab Immunol 6: 437-439. [Crossref]

16. Carrilho MR, Carvalho RM, de Goes MF, di Hipólito V, Geraldeli S, et al. (2007) Chlorhexidine preserves dentin bond in vitro. J Dent Res 86: 90-94. [Crossref]

17. Hebling J, Pashley DH, Tjäderhane L, Tay FR (2005) Chlorhexidine arrests subclinical degradation of dentin hybrid layers in vivo. $J$ Dent Res 84: 741-747. [Crossref]

18. Prasansuttiporn T, Nakajima M, Kunawarote S, Foxton RM, Tagami J (2011) Effect of reducing agents on bond strength to NaOCl-treated dentin. Dent Mater 27: 229-234. [Crossref]

19. Loguercio AD, Luque-Martinez I, Muñoz MA, Szesz AL, Cuadros-Sánchez J, Reis A (2014) A comprehensive laboratory screening of three-step etch-and-rinse adhesives. Oper Dent 39: 652-662. [Crossref]

20. Breschi L, Cadenaro M, Antoniolli F, Sauro S, Biasotto M, et al. (2007) Polymerization kinetics of dental adhesives cured with LED: correlation between extent of conversion and permeability. Dent Mater 23: 1066-1072. [Crossref]

21. Sanabe ME, Costa CA, Hebling J (2011) Exposed collagen in aged resin-dentin bonds produced on sound and caries-affected dentin in the presence of chlorhexidine. J Adhes Dent 13: 117-124. [Crossref]

22. Carrilho MR, Carvalho RM, Tay FR, Pashley DH (2004) Effects of storage media on mechanical properties of adhesive systems. Am J Dent 17: 104-108. [Crossref]

23. Zhang SC, Kern M (2009) The role of host-derived dentinal matrix metallo-proteinases in reducing dentin bonding of resin adhesives. Int J Oral Sci 1: 163-176. [Crossref]

24. Bouillaguet S, Duroux B, Ciucchi B, Sano H (2000) Ability of adhesive systems to seal dentin surfaces: an in vitro study. $J$ Adhes Dent 2: 201-208. [Crossref] 
25. Hashimoto M, Ito S, Tay FR, Svizero NR, Sano H, et al. (2004) Fluid movement across the resin-dentin interface during and after bonding. J Dent Res 83: 843-848. [Crossref]

26. Carrilho MR, Tay FR, Sword J, Donnelly AM, Agee KA, et al. (2007) Dentine sealing provided by smear layer/smear plugs vs. adhesive resins/resin tags. Eur J Oral Sci 115: 321-329. [Crossref]

27. Cavalheiro A, Vargas MA, Armstrong SR, Dawson DV, Gratton DG (2006) Effect of incorrect primer application on dentin permeability. $J$ Adhes Dent 8: 393-400. [Crossref]

28. Jacobsen T, Söderholm KJ (1995) Some effects of water on dentin bonding. Dent Mater 11: 132-136. [Crossref]

29. Carrilho MR, Carvalho RM, Sousa EN, Nicolau J, Breschi L, et al. (2010) Substantivity of chlorhexidine to human dentin. Dent Mater 26: 779-785. [Crossref]

30. Tallant C, Marrero A, Gomis-Rüth FX (2010) Matrix metalloproteinases: fold and function of their catalytic domains. Biochim Biophys Acta 1803: 20-28. [Crossref]

31. Carvalho RV, Ogliari FA, de Souza AP, Silva AF, Petzhold CL, et al. (2009) 2-hydroxyethyl methacrylate as an inhibitor of matrix metalloproteinase-2. Eur J Oral Sci 117: 64-67. [Crossref]
32. Sadek FT, Braga RR, Muench A, Liu Y, Pashley DH, et al. (2010) Ethanol wet-bonding challenges current anti-degradation strategy. J Dent Res 89: 1499-1504. [Crossref]

33. Kim J, Uchiyama T, Carrilho M, Agee KA, Mazzoni A, et al. (2010) Chlorhexidine binding to mineralized versus demineralized dentin powder. Dent Mater 26: 771-778. [Crossref]

34. Xu Y, Xu G, Liu L, Xu D, Liu J (2010) Anti-invasion effect of rosmarinic acid via the extracellular signal-regulated kinase and oxidation-reduction pathway in Ls174-T cells. J Cell Biochem 111: 370-379. [Crossref]

35. Petersen M, Simmonds MS (2003) Rosmarinic acid. Phytochemistry 62: 121-125. [Crossref]

36. Aruoma OI, Cuppett SL (1997) Antioxidant methodology: in vivo and in vitro concepts Champaign, IL, USA: AOCS Press.

37. [Crossref] Yu YM1, Lin HC, Chang WC (2008) Carnosic acid prevents the migration of human aortic smooth muscle cells by inhibiting the activation and expression of matrix metalloproteinase-9. Br J Nutr 100: 731-738.

Copyright: (C2017 Senawongse P. This is an open-access article distributed under the terms of the Creative Commons Attribution License, which permits unrestricted use, distribution, and reproduction in any medium, provided the original author and source are credited. 